\title{
Examining the Effectiveness of English Language Improvement Curriculum Materials on the English Proficiency of Students
}

\author{
Lina Lafta Jassim \\ College of Art, University of Thi-Qar, Iraq.
}

How to cite this paper: Lina Lafta Jassim. (2020) Examining the Effectiveness of English Language Improvement Curriculum Materials on the English Proficiency of Students. Journal of Humanities, Arts and Social Science, 4(2), 126-142.

DOI: 10.26855/jhass.2020.07.007

Received: September 1, 2020

Accepted: October 2, 2020

Published: November 9, 2020

*Corresponding author: Lina Lafta Jassim, College of Art, University of Thi-Qar, Iraq.

Email:

Lfnar83@gmail.com;

Lina.art@utq.edu.iq

\begin{abstract}
This study aims to examine the effectiveness of materials in Texas. Using local linear matching, we find that schools that do not purchase any ELI curricula have significantly lower English language proficiency scores relative to schools that purchase state-adopted ELI materials. These results are robust across various matching models-inverse probability weights with regression adjustment, kernel matching, and nearest neighbor matching - and a comparative interrupted time series design. There is no major difference between schools adopt the two most common English language development curricula—Rigby On Our Way to English and National Geographic Reach. This study suggests that emergent bilinguals (EBs) who attend schools that have instructional materials that explicitly foreground English language proficiency standards outperform those in schools that do not have such materials.
\end{abstract}

\section{Keywords}

Achievement, English Language, Curriculum, Education, Social Sciences, Schools

\section{Introduction}

Emergent bilinguals ${ }^{1}$ are one of the fastest growing and one of the most underserved student populations in the United States (Capps et al., 2005; Genesee, Lindholm-Leary, Saunders, and Christian, 2005; National Education Association, 2008). Since 2000, the emergent bilingual (EB) population in American public schools has grown by 28\% (National Center for Education Statistics, 2019) and now accounts for 9.6\% of all public school students in the United States. Of all EBs in the United States, 78\% are Hispanic, and the majority qualify for free or reduced lunch. Emergent bilinguals are "triply segregated"-more likely to attend schools with other EBs, minorities, and low-income students (Orfield, 2001; Orfield \& Lee, 2006; Ríos-Aguilar \& Gándara, 2012). Results from the 2019 National Assessment of Educational Progress show that EB-non EB achievement gaps are as large as gaps for students who do and do not receive free or reduced-price lunch.

\footnotetext{
${ }^{1}$ Following Burke, Morita-Mullaney, and Singh. (2016). We use the term emergent bilingual in lieu of the following: English language learner (ELL), English as a second language (ESL), and limited English proficient (LEP). Scholars have objected to the terms "limited English proficient" and "English language learner" (Garcia 2009) due to its deficit-framing of the linguistic abilities of emergent bilinguals. The terms also suggest that English proficiency is the only desired outcome for this population of students (Menken and Solorza, 2014). Referring to this group of students by an additive name that does not focus on its limitations is an important step towards the decentering of English monolingual norms. Similar to Burke et al. (2016), we use the term emergent bilingual with two exceptions. First, the terms ELL, ESL, and LEP may be used when referencing federal and state laws. Second, the terms ELL, ESL, and LEP may be used in the literature review if the authors of the studies use the terms.
} 
To improve the educational outcomes of EBs, federal court cases have required that programs for EBs be effective. Castañeda v. Pickard (1981) mandated that educational programs for EBs be based on sound educational theory, implemented effectively, and tested for program efficacy. Since research has shown that textbooks influence the content and methods that teachers use in the classroom (Alajmi, 2009; Alajmi, 2012; Robitaille \& Travers, 1992), English language development (ELI) textbooks can play an integral role in program efficacy. This paper addresses the third mandate in the Castañeda v. Pickard (1981) ruling by measuring the relationship between ELI curriculum materials and EBs' English proficiency. Though Texas' educational policies refer to English language development as English as a second language, we use the term ELI in this study to refer to language programs provided to EBs to attain English proficiency. ELI is a more accurate term because English may not necessarily be the second language of EBs.

The association between textbook quality and student achievement has important implications for local education agencies. Since the costs of textbooks across publishers are quite similar, districts have the potential to increase student achievement at minimal marginal cost (Chingos \& Whitehurst, 2012). Furthermore, efforts to improve the achievement of EBs by making better curriculum choices may face fewer challenges compared to other alternatives (e.g., extending the school day, increasing the number of bilingually-certified teachers), which may be less feasible or politically palatable. Though a few studies have looked at the relationship between mathematics textbooks and student achievement (Agodini et al., 2010; Bhatt \& Koedel, 2012; Bhatt, Koedel, \& Lehmann, 2013; Blazar et al., 2019; Koedel et al., 2017), no studies have examined the effect of ELI textbooks on the English proficiency of EBs. Castañeda v. Pickard (1981) mandated that educational programs for emergent bilinguals be tested for program efficacy. Since English language development (ELI) curricular materials are one part of an instructional program, we assess this mandate by examining the effectiveness of ELI materials in Texas. This study seeks to fill this gap by answering the following research questions:

1). To what extent do English proficiency outcomes differ between schools purchase any ELI curricular materials and schools that purchase state-adopted curricular materials?

2). To what extent do ELL English proficiency outcomes differ between schools that use the two most popular ELI curricular materials (Rigby and National Geographic)?

\section{Background Information}

\subsection{Research on Textbook Efficacy}

The choice of curriculum materials can significantly affect student achievement. Five recent rigorous, empirical studies examine the relationship between textbooks and student academic outcomes. First, Agodini et al. (2010) use a randomized control trial across 12 districts to compare the effects of four elementary mathematics on student achievement in grades 1 and 2. The authors find that math curricula correspond to large differences in student academic achievement. For example, by the end of grade 2, certain curricula were associated with an increase of 0.17 standard deviations in student test scores. Three quasi-experimental studies use matching techniques in Indiana (Bhatt \& Koedel 2012), Florida (Bhatt, Koedel, \& Lehmann, 2013), and California (Koedel et al., 2017) and find positive effects of one of the studied elementary mathematics textbooks in each state (on the order of .05 to .10 standard deviations per year, and larger for low-income students). The largest and most recent study (Blazar et al., 2019), in contrast, found no impacts of elementary mathematics textbooks across six states. Together, these findings imply that the choice of textbook, at least in elementary mathematics, may have direct impacts on student achievement. Though a few studies have looked at the relationship between mathematics textbooks and student achievement, to our knowledge no studies have examined the effect of ELI textbooks on EBs' English language proficiency. This study would be the first to use quasi-experimental methods to assess the effectiveness of ELI instructional materials.

\subsection{State Textbook Adoptions}

In the United States, some state conduct state-level textbook adoptions (which are typically advisory for schools and districts) and some states allow for complete local control of textbook purchases (Zeringue et al., 2010). Texas is one of the two largest states, and it conducts an advisory state adoption (meaning the state puts out a list of approved materials but districts can purchase materials on or off the list). Historically, publishers were thought to tailor their books to the needs and preferences of the Texas State Board of Education and concentrate their selling efforts in Texas (Bowler, 1978; Stein et al., 2001). However, it should be noted that Texas' national influence on textbook adoption may have waned since the adoption of Common Core State Standards (CCSS). While forty-two states and the District of Columbia have adopted the CCSS, Texas has not. 


\subsection{District Textbook Adoptions}

Once the Texas State Board of Education decides which instructional materials are approved by the state, district leaders can decide which curricula they want to adopt for their particular district. Textbook adoptions in Texas districts (except in charter schools) are uniform adoptions at the district level, meaning that all schools in the district use the same materials (Texas Education Agency, 2015). Unlike in other subjects, districts are not mandated to purchase any ELI textbooks at all, and they can also purchase on or off the state-approved list (Texas Education Agency, 2011). Given the great flexibility that districts have over ELI textbook adoption, it is important to understand how the extra autonomy has impacted the English proficiency of EBs.

Prior research has shown that district leaders consult a variety of sources to make textbook adoption decisions. Using data from over 150 interviews with curriculum decision-makers in eight states, Zeringue et al. (2010) found that district leaders had limited information on textbook efficacy and, therefore, tended to make adoption decisions based on other factors such as teacher acceptance and advice from neighboring districts. In addition, Zeringue et al. (2010) found that $80 \%$ of curriculum leaders sought out information about textbook use, effectiveness, and acceptance of the materials. Thus, if more research was available regarding textbook efficacy, curriculum leaders may use this information to make better choices.

\subsection{ELD Textbooks in Texas}

The 2011-2012 school year is the most recent ELI textbook adoption cycle in the state of Texas. During this adoption cycle, the state released a list of seven state-approved ELI curricula. Of the seven, two are online programs and five are traditional, textbook curricula. The textbooks vary along several dimensions including number of lessons on forms of English, opportunities to learn new vocabulary words, and the ratio of listening/speaking activities to reading/writing activities. Of the five traditional curricula, Rigby On Our Way to English and National Geographic Reach are the most popular, comprising $69 \%$ of adoption patterns in Texas (see Table 1).

Table 1. Number of schools that adopted each curriculum in Texas for grade $3(\mathrm{~N}=1,253)$

\begin{tabular}{ccc}
\hline Schools & Number of & \% of Schools \\
\hline State-adopted Texts & & 551 \\
National Geographic Reach & 310 & $44 \%$ \\
Rigby On Our Way to English & 83 & $25 \%$ \\
McGraw-Hill Texas Treasure Chest & 20 & $7 \%$ \\
Pearson Longman Cornerstone & 0 & $2 \%$ \\
Santillana Spotlight on English & 0 & $0 \%$ \\
Achieve3000 (online) & 0 & $0 \%$ \\
ESL Reading Smart & 16 & $1 \%$ \\
Non-State-Adopted Book & 253 & $20 \%$ \\
No ELD textbook adoption & & $0 \%$ \\
\hline
\end{tabular}

With 515 schools across 48 districts adopting National Geographic Reach, it is the most frequently adopted ELI curricula and represents $44 \%$ of adoptions. The author of this book also authored the widely-used Sheltered Instruction Observation Protocol (SIOP), which is designed to improve instruction for EBs. National Geographic Reach was first published in 2011. A student anthology in the National Geographic Reach series is usually divided into eight units. Each unit includes multiple opportunities to use language frames, share aloud with a partner, learn conversational and academic vocabulary, and practice language-learning strategies (e.g., predicting, rereading and retelling). The anthology includes a mix of fiction and non-fiction texts.

With 313 schools across 37 districts adopting Rigby On Our Way to English, it is the second most popular ELI curricula in Texas. Rigby is a registered trademark of Houghton Mifflin Harcourt. On Our Way to English is marketed as a comprehensive ELI program that focuses on academic language, vocabulary development, content-based instruction, and oral language. The text is typically divided into eight units with each unit providing opportunities to engage with fiction and non-fiction texts. On Our Way to English was first published in 2011 and is available in a 
Texas-specific version and a national version. In contrast, a Texas-specific version of National Geographic Reach does not exist.

\section{Data}

The data for the proposed study come from the state of Texas. Texas serves roughly 5,400,000 students across approximately 1,250 public school districts. The racial composition of students in Texas' public schools is as follows: 53\% Hispanic, 27\% White, 13\% Black, 4\% Asian, and 2\% multiracial (National Center for Education Statistics 2019). Roughly $17 \%$ of students in Texas' public schools are identified as English language learners.

Texas is an ideal state for the study of English language development curriculum materials on EBs' English proficiency for several reasons. First, Texas is home to approximately 900,000 EBs, the second highest number of EBs in the United States ${ }^{2}$. Second, the textbook adoption process is centralized in Texas, which allows for a more manageable analysis. Third, Texas has a large number of school districts, which allows for adequate statistical power for student achievement analyses. Fourth, since Texas grants great autonomy to districts over ELI textbook adoption, there is variation in the kinds of ELI instructional materials that are adopted. In the years under study, districts in Texas report using 7 different state-approved ELI curricula and 21 different non-state-approved ELI curricula.

Textbook information was collected from districts using the Texas Education Agency (TEA) online data portal. The TEA collects information, which is publicly available through Freedom of Information Law (FOIL) request, on instructional materials allotment (IMAT). We obtained ELI textbook purchases for the years 2011-2015. The following textbook information is available for each district: publisher, textbook title, subject, grades used, unit price, quantity of units purchased, and adoption year. We found 418 districts on the IMAT list for years 2011-2015, which left 810 districts with missing information on ELI textbook adoption. Since the IMAT report only captures purchases made using state funds, it does not capture instructional materials that were purchased using local funds nor instructional materials that were purchased prior to 2011. Therefore, it cannot be assumed that districts that are not on the2011-2015 IMAT list did not purchase ELI instructional materials. The other 810 districts might have purchased ELI textbooks prior to 201l. Alternatively, these 810 districts may not have purchased any ELI instructional materials. To obtain information on ELI instructional materials for the remaining 810 districts, we submitted Public Information Requests to each district with missing ELI textbook information and received responses from 737 districts, yielding an overall district response rate of $94 \%$.

\subsection{Analytic Sample}

We focus out analysis on elementary schools in Texas that serve EBs. Since the study focuses on elementary English language development books, we drop middle and high schools from the sample as elementary ELI textbooks are intended for elementary-aged students and are typically not purchased for older students. In addition, elementary schools that do not have EBs $(\mathrm{n}=82)$ are excluded from the study since they do not have a need for ELI curricular materials.

Table 2 provides details about the construction of the analytic sample starting with the universe of schools in Texas that are eligible for the study $(\mathrm{N}=3,085)$. After four exclusion criteria were applied ${ }^{3}, 1,253$ elementary schools $(41 \%)$ remain in the sample. First, schools that did not adopt the same ELI curriculum in grades K-3 were dropped from the sample. Roughly three percent of schools were excluded because they indicated using more than one ELI curricula in grades K-3. Though it is possible to examine mixed-treatment effects, there are too few schools for an effective analysis.

Second, elementary schools that did not report English language proficiency scores for spring 2015 were eliminated from the study. There are two scenarios in which the TEA would mask Texas English Language Proficiency Assessment System (TELPAS) scores: 1). When few students in a group are evaluated and it may be possible to identify particular students or 2). When all the students in a group have the same result (Texas Education Agency, 2015). Masking refers to the use of special symbols to conceal data to protect student confidentiality. Due to masking of student data, 48\% of schools did not report TELPAS scores for spring 2015 and were, thus, dropped from the study.

Third, less than one percent of schools were eliminated from the study due to missing information regarding ELI

\footnotetext{
${ }^{2}$ With over 1.5 million EBs, California has the highest number of EBs in the United States (National Center for Education Statistics, 2019).

${ }^{3}$ The four exclusion criteria used in this study are similar to the ones used in Koedel et al.'s (2017) study on the effectiveness of math textbooks in California.
} 
adoption. Specifically, 21 schools or $0.7 \%$ of the sample were dropped due to missing ELI textbook information. Though public information requests were submitted to all districts in Texas with missing ELI textbook information, 3 districts out of the remaining districts in the study did not respond. These 3 districts represent 21 schools. Given these data restrictions, the results from this study are only generalizable to elementary schools in Texas that adopted the same ELI curriculum in grades K-3, reported TELPAS scores in spring 2015, and reported ELI textbook adoption.

Table 2. Construction of the Analytic Sample

\begin{tabular}{|c|c|c|c|c|}
\hline & Schools & $\%$ of total & Districts & $\%$ of total \\
\hline Initial Universe & 3,085 & & 651 & \\
\hline \multicolumn{5}{|l|}{ Reason for exclusion } \\
\hline Non-uniform adopted, grades k-3 & -95 & 3.1 & 47 & 7.2 \\
\hline \multicolumn{5}{|l|}{ Missing outcome variable (TELPAS } \\
\hline 2015) & -1486 & 48.2 & 410 & 63.0 \\
\hline Missing textbook information & -21 & 0.7 & 3 & 0.5 \\
\hline HISD or DISD & -230 & 7.5 & 2 & 0.3 \\
\hline 0.03Missing covariates & 0 & 0 & 0 & 0 \\
\hline Final Analytic Sample & 1,253 & 40.6 & 189 & 29.3 \\
\hline
\end{tabular}

Fourth, Houston Independent School District (HISD) and Dallas Independent School District (DISD) were dropped because both districts are much larger than all other districts in the state which made it difficult to find comparable matches. After dropping HISD and DISD from the sample, 1,253 schools and 191 districts remain. The final analytic sample retains $41 \%$ of the universe of schools and $29 \%$ of the universe of districts.

\subsection{ELD Textbook Adoption Patterns}

In the final analytic sample, we find that the majority of elementary schools in Texas that service EBs purchase state-adopted ELI materials (see Table 1). While roughly 1\% of the final analytic sample purchased materials that were not on the state-adopted list, $79 \%$ of schools purchased materials on the state-adopted list. Approximately $20 \%$ of schools in the final sample did not purchase any ELI materials even though they did have students identified as ELL in their school.

Of the ELI materials on the state-adopted list, National Geographic Reach and Rigby On Our Way to English were the most popular with $69 \%$ of schools in the final analytic sample purchasing from one of these two publishers.

\subsection{School-Level Variables}

Though ELI textbook adoption typically occurs at the district level, we match at the school level for two reasons. First, matching is a "data hungry" process that requires a large sample size (Heckman, Ichimura, \& Todd, 1998). Second, schools within the same district can vary greatly in their demographics, test scores, teacher experience, etc. Conducting the analysis at the school level allows us to adjust for both school- and district-level characteristics (Bhatt \& Koedel, 2012; Bhatt, Koedel, \& Lehmann, 2013).

School-level data are drawn from the Texas Education Agency online data portal. Information about students and teachers are available at the school level. With regards to teachers, the following information is available: experience, gender, race, and credential type. In terms of students, the following information is available at the school level: race, gender, free/reduced price lunch eligibility, special education eligibility, English language learner status, district average math and reading score on the State of Texas Assessments of Academic Readiness (STAAR), and district average English language proficiency scores on the TELPAS (Texas English Language Proficiency Assessment System). Since the last year of ELI textbook adoption in Texas was the 2011-2012 school year, we use achievement and demographic data from 2010-2011 to match schools.

\subsection{Outcome Variables}

School-average composite scores on the spring 2015 TELPAS assessment serve as the outcome variable. The TELPAS assessment is delivered on a yearly basis to monitor EBs' progress in attaining English proficiency. Since there are four language modalities-listening, speaking, writing, and reading - the TELPAS exam is divided into four sections. Students are given a rating of 1-4 on each subtest where 1 represents Beginning, 2 represents Inter- 
mediate, 3 is Advanced, and 4 represents Advanced High (TEA, 2016). In order to arrive at the composite score, TEA weights each section as follows: listening (0.10), speaking (0.10), reading (0.50), and writing (0.30). Using student-level TELPAS scores, we create school-average composite TELPAS scores which are approximately normally distributed (see Figure 1).

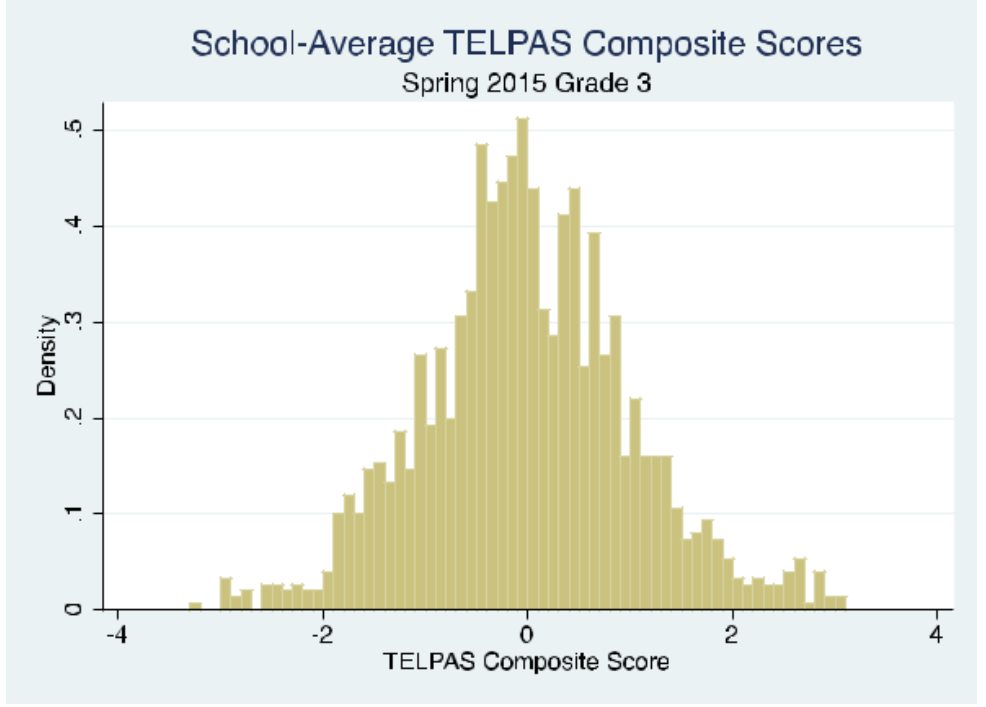

Figure 1. Distribution of Outcome Variable.

Since the STAAR reading assessment may appear to be very similar to the TELPAS exam, we briefly clarify the differences between the two assessments and justify using TELPAS scores as the outcome variable. While the reading portion of the STAAR assesses students' mastery of content standards for English language arts, the TELPAS assessment focuses on language standards - not content standards. The reading portion of the STAAR assessment only measures reading abilities and does not include a listening and speaking portion. Since the TELPAS exam covers all four language modalities (listening, speaking, reading, and writing), the TELPAS is better positioned to assess English proficiency. Increased English proficiency may lead to greater access to content standards; therefore, it is possible that increases in TELPAS scores lead to increases in STAAR reading scores. However, since TELPAS scores are a more direct measure of English proficiency than STAAR reading scores, we use TELPAS scores as the outcome variable.

\subsection{Research Design}

To model the association between various ELI curriculum materials and EBs' English proficiency, we use local linear matching. Bhatt and Koedel (2012) used a similar matching approach to evaluate relative curriculum effectiveness in the state of Indiana. Since districts can self-select into the treatment (i.e., the ELI textbook), selection bias may affect our coefficient estimates. Matching on school characteristics reduces group differences across all the observed variables used in the propensity score equation (Shadish, Cook, \& Campbell, 2002). Matching can allow for causal inferences if the conditional independence assumption is met (Heckman, Ichmura, \& Todd, 1997; Rosenbaum \& Rubin, 1983).

The conditional independence assumption requires that potential outcomes be independent of textbook choice conditional on the observables. In other words, the assumption requires that all relevant variables be included in the model. The conditional independence assumption will not be satisfied if unobserved characteristics influence both the treatment and the outcome. By using an estimated propensity score, we can match schools based on their observable characteristics to minimize the likelihood that unobserved characteristics may influence the outcome. Matching has two main advantages over a simple regression analysis. First, matching has fewer restrictions on functional form (Black \& Smith, 2004). Second, matching can more accurately predict the relationship between covariates and the outcome variable by restricting the influence of noncomparable treatment and control units (Black \& Smith, 2004).

Of schools that adopt ELI materials in the final analytic sample, 92\% adopted new ELI curricula in 2011-2012. Thus, third graders in 2014-2015 will have potentially been exposed to the ELI curricula for four years. If an ELI curriculum is effective, then districts using this curriculum should have higher TELPAS scores for their ELLs 
compared to districts that did not adopt this particular curriculum.

Following Bhatt and Koedel (2012), we use the term "total treatment effects" to account for the possibility of the estimates capturing systematic differences between treatment and control schools. For example, if one curriculum has a teacher's guide that is easier to navigate, the estimates will reflect this difference. Based on the series of falsification tests we conducted for the study, we find little evidence to suggest that there are systematic differences between treatment and control schools. However, it should be noted that the estimates from this study will capture "total treatment effects”.

\subsection{Propensity Score Estimation}

In order for propensity score matching to yield unbiased estimates of the effectiveness of ELI textbooks, two types of covariates should be included: 1). pretest measures of the outcome variable and 2). direct measures of the selection process (Cook \& Steiner, 2010; Glazerman, Levy, \& Myers, 2003; Steiner \& Cook, 2013). The first type of covariate is easily obtainable through TEA. We include school average TELPAS composite scores from spring $2011^{4}$ (pre-adoption) in the selection model. The second type of covariate is slightly harder to obtain. Steiner and Cook (2013) suggest investigating the actual selection process before starting the study because the omission of important variables can seriously increase bias in the estimates (Heckman, Ichimura, \& Todd, 1997). Shadish and Steiner (2010) recommend interviewing relevant individuals to identify factors that influence selection into treatment and studying the pertinent research literature. In addition, economic theory and previous empirical findings should guide the choice of variables to include in the propensity score estimation ${ }^{5}$ (Caliendo \& Sabine, 2008).

Heckman et al. (1997) find that selection models that include variables related to treatment assignment are better able to predict treatment assignment than models that only include demographic characteristics like education and race. The covariates that are used to estimate the propensity score should include all of the key factors affecting both the outcome variable and the treatment assignment (Smith \& Todd, 2005). When creating a list of covariates for the propensity score estimation, there is a tradeoff between bias and variance. Including an irrelevant variable can lead to increased variance, while excluding a potentially important confounder can lead to increased bias.

We investigate the selection mechanism using two methods. First, we conduct in-depth interviews with 28 district leaders in Texas which we describe in the following paragraphs. Second, we review previous research on textbook effectiveness to identify potential covariates (Rubin, 2001).

\subsection{District Leader Interviews}

To understand the factors influencing ELI textbook adoption, we conducted 28 in-depth interviews with district leaders using structured open-ended interviewing protocols. We focus on district leaders because textbook adoption typically occurs at the district level in the state of Texas. The districts selected for interviews represented variation along two dimensions: percentage of EBs (e.g., low and high) and ELI textbook adoption patterns (4 possible patterns) — yielding 8 total cells. Using proportional stratified sampling, we selected 2-8 districts from each cell, giving a total of 28 districts. Interviews lasted approximately 45 minutes and were audio recorded and transcribed. Interview data were analyzed using NVivo software.

In the initial cycle of interview data review, which required at least three readings of the full transcript, we used structural codes, which entail little interpretation. Structural coding "acts as a labeling and indexing device, allowing researchers to quickly access data likely to be relevant to a particular analysis from a larger data set" (Namey et al., 2008, p. 141). Though interviews covered a range of topics, including program model for EBs, we subjected the entire transcript to this initial coding, since district leaders spoke about instructional materials in response to questions not directly about instructional materials (e.g., bilingual model). The first cycle of coding revealed 27 structural codes related to ELD textbook adoption. These structural codes were further categorized and analyzed in the second stage of review.

In the second cycle of coding, the primary goal is to create categorical, thematic, and conceptual organization from the array of codes that emerged from first cycle coding (Saldana, 2013). We used pattern coding in the later stages of data analysis to group codes into a smaller number of themes. Five main factors emerge from the interview data. The following list of factors shape district leaders' decisions around ELI textbook adoption: number of EBs, academic

\footnotetext{
${ }^{4}$ The higher the correlation between pretest and posttest, the greater the bias reduction (Steiner \& Cook, 2013). The correlation between school-average TELPAS scores in 2011 and school-average TELPAS scores in 2015 is 0.43.

${ }^{5}$ We use a binomial logistic model for all research questions to estimate the propensity score.
} 
achievement of EBs, district leaders' beliefs about second language acquisition, district budget, and program model for EBs. We briefly discuss each of these factors in the paragraphs that follow.

One factor that district leaders take into consideration when deciding which ELI curriculum to adopt is the number of EBs in their district. Six out of 28 district leaders cited EB enrollment as a factor for ELI textbook adoption. For example, a curriculum facilitator in district 15 states that "the number of students that we have identified [as ESL]" is a major determinant in whether or not ELI materials are purchased. This district leader elaborates, "If there's a high number of students then, of course, the need [for ELI instructional materials] would be greater. But if there are a low number of students then our expert teachers in the bilingual department will be able to modify their instruction to meet the needs of their ESL or ELL students". For this particular district, bilingual teachers are expected to meet the linguistic needs of EBs in the event that ELI materials are not purchased. To model the treatment assignment, we include the number of EBs — at both the school and district level — in the propensity score.

Second, district leaders consider EBs' academic achievement when making curricular decisions. Eight out of 28 district leaders report EBs' test scores (e.g., scores on the STAAR test, scores on language proficiency tests) as a factor that influences ELI textbook adoption. District Leader 18 shares, "We're a pretty successful district when you look at state scores. What we have found is that a lot of the times the basals don't get you where you need to get. We pull from a lot of different resources". Since this district leader seems to be satisfied by her district's test scores, she does not see a need to purchase ELI materials. Instead, she believes that the district's current curriculum, which seems to be a mixture of various resources, is sufficient to meet the needs of the students. Furthermore, District Leader 12 looks at "proficiency projections as well as grade-level means" to determine whether or not ELI materials need to be purchased. We include pre-treatment school and district average reading achievement on the Texas Assessment of Knowledge and Skills ${ }^{6}$ (TAKS) and TELPAS in the estimation of the propensity score.

A third factor that that influences ELI materials purchasing is district leaders' beliefs about second language acquisition. Thirteen out of 28 district leaders use their beliefs about second language acquisition to make decisions about ELI materials. Some leaders believe that second language learning is not much different from first language learning; thus, EBs do not need additional materials. For instance, District Leader 10 states, "We don't have a particular program that we offer or provide for [EBs]...We just rely on good instruction.” This district did not purchase any ELI curricular materials because school administration believes that the instruction that all students receive should be effective for EBs as well. Since it is difficult to directly assess district leaders' beliefs about second language acquisition for every district in Texas, we adjust for the following Census characteristics at the district level: median income and the percentage of non-English speakers in the district. Since beliefs about language learning may vary based on professional status (Horwitz, 1999), we include median income to proxy for professional status. As classroom and social peers influence learning (Arnold, 1999), we include the percentage of non-English speakers in the district as a means of capturing the variation in beliefs about second language acquisition.

Fourth, cost is another factor that districts weigh in their decision to purchase ELI texts. Sixteen out of 28 district leaders report that cost is an important consideration in ELI materials purchasing. An elementary school principal from District 21 states, "We are a small, rural district. So we also have to think about using our money wisely too...the main thing we have to make sure of is that it's something we can afford. Price would be the big decision-maker". Along the same lines, District Leader 15 states that "the budget is always a factor". We include district per pupil revenue along with district instructional expenditures to capture each district's financial ability to purchase ELI materials.

Fifth, a district's program model for EBs emerges as another factor influencing ELI materials purchasing. Eight out of 28 district leaders state that the district's program model for EBs impacts whether or not ELI materials are adopted. Districts that have bilingual programs are less likely to purchase ELI texts because they are already purchasing texts in other languages, usually Spanish, for their EBs which reduces the amount of money that is available for ELI texts. In addition, districts that have bilingual programs also have bilingual teachers and some districts use bilingual teachers' knowledge of second language acquisition to supplant ELI instructional materials. In the propensity score estimation, we include a dichotomous variable indicating the presence of a bilingual program.

In addition to district leader interviews, prior research on textbook adoption can help to model the selection mechanism (Caliendo \& Sabine, 2008; Heckman, Ichimura, \& Todd, 1997). For instance, Bhatt and Koedel (2012), in modeling the association between textbook adoption and achievement, use the following covariates in their propensity score model: enrollment, attendance rates, demographics (race, language status, free lunch status), achievement

${ }^{6}$ In spring 2012, the TAKS exam was replaced by the STAAR. 
outcomes from prior years, per pupil expenditures, and Census measures (e.g., median household income, share of adults with a high school diploma).

Table 3. Covariate-by-Covariate Balancing Details for the Comparison Between No ELI Text and State-Adopted ELI Text

\begin{tabular}{|c|c|c|c|c|c|c|}
\hline & Mean for & Mean for & Standardize & & & Variance(T) \\
\hline & Treated & Control & d difference & & & Variance(C) \\
\hline $\begin{array}{c}\text { School Characteristics } \\
\text { Enrollment }\end{array}$ & 619.59 & 632.34 & -0.072 & -0.85 & $0.397^{* * *}$ & 0.77 \\
\hline Share ELL & 0.41 & 0.41 & -0.017 & -0.2 & $0.841^{* * *}$ & 1.49 \\
\hline Share Hispanic & 0.68 & 0.72 & -0.172 & -1.96 & $0.05^{* *}$ & 1.15 \\
\hline Share SPED & 0.07 & 0.07 & 0.09 & 0.96 & $0.335^{* * *}$ & 1.04 \\
\hline Average Teacher Years of Experience & 10.69 & 10.99 & -0.112 & -1.13 & $0.257^{* * *}$ & 0.86 \\
\hline Number of Bilingual Teachers & 24.24 & 28.67 & -0.255 & -2.5 & $0.013^{* * *}$ & 0.78 \\
\hline Bilingual Program Indicator & 0.9 & 0.94 & -0.107 & -1.47 & $0.142^{* * *}$ & -- \\
\hline $\begin{array}{c}\text { School Outcomes } \\
\text { School Average Math Score }\end{array}$ & 590.62 & 592.07 & -0.05 & -0.56 & $0.578^{* * *}$ & 1.08 \\
\hline School Average ELL Math score & 586.74 & 587.76 & -0.028 & -0.3 & $0.764^{* * *}$ & 1.02 \\
\hline School Average ELA Score & 601.15 & 599.41 & 0.054 & 0.61 & $0.539^{* * *}$ & 1.26 \\
\hline School Average ELL ELA Score & 587.26 & 586.19 & 0.025 & 0.26 & $0.793^{* * *}$ & 0.87 \\
\hline $\begin{array}{c}\text { District Characteristics } \\
\text { District Enrollment }\end{array}$ & $31,360.03$ & $29,779.48$ & 0.039 & 0.69 & $0.488^{* * *}$ & 0.74 \\
\hline Share ELL & 22.44 & 21.03 & 0.112 & 1.26 & $0.21^{* *}$ & 1.76 \\
\hline Per Pupil Expenditure & $10,924.73$ & $11,211.18$ & -0.118 & -1.33 & $0.183^{* * *}$ & 3.77 \\
\hline Total Revenue Per Pupil & $1,348.79$ & $1,399.63$ & -0.093 & -0.92 & $0.36^{* *}$ & 1.4 \\
\hline Urbanicity & 4.08 & 3.93 & 0.051 & 0.5 & $0.618^{* * *}$ & 0.58 \\
\hline $\begin{array}{c}\text { District Outcomes } \\
\text { District Avg TELPAS Score }\end{array}$ & 3.08 & 3.08 & -0.004 & -0.04 & $0.966^{* * *}$ & 0.93 \\
\hline District Average Math Score & 596.02 & 595.68 & 0.018 & 0.2 & $0.844^{* * *}$ & 1.03 \\
\hline District Avg Math Score for ELLs & 587 & 587.13 & -0.006 & -0.07 & $0.945^{* * *}$ & 1.61 \\
\hline District Average ELA Score & 609.87 & 608.22 & 0.077 & 0.87 & $0.384^{* * *}$ & 1.07 \\
\hline District Avg ELA Score for ELLs & 587.98 & 585.54 & 0.104 & 1.12 & $0.262^{* * *}$ & 1.46 \\
\hline $\begin{array}{c}\text { District-Area Characteristics (Census) } \\
\text { Median Household Income }\end{array}$ & $47,976.89$ & $46,785.11$ & 0.08 & 0.82 & $0.413^{* * *}$ & 1.09 \\
\hline Share Non-English Speakers & 42.85 & 43.21 & -0.014 & -0.15 & $0.879^{* * *}$ & 1.13 \\
\hline Propensity score & 0.34 & 0.34 & 0 & 0.00 & $0.997^{* * *}$ & 1 \\
\hline
\end{tabular}

Notes. ${ }^{* *} \mathrm{p}<0.01 ;{ }^{* * *} \mathrm{p}<0.001$.

Table above contains the final list of covariates used to estimate the propensity score.

\subsection{Balancing Tests}

We test for covariate balance using three different tests. Multiple tests are used because there is no clearly preferred test for balance, and different tests may yield different results (Smith \& Todd, 2005b). Since there are two research 
questions, the propensity score must be calculated separately. While the first propensity score measures the probability of not choosing an ELI text, the second propensity score measure the likelihood of adopting Rigby On Our Way to English. For this reason, covariate balancing is assessed twice (Table 3 and Table 4).

Table 4. Covariate-by-Covariate Balancing Details for the Comparison Between Rigby On Our Way to English and National Geographic Reach

\begin{tabular}{|c|c|c|c|c|c|c|}
\hline & Mean for & Mean for & Standardize & t-test & p-value & Variance(T)/ \\
\hline & Treated & Control & d difference & & & Variance(C) \\
\hline $\begin{array}{c}\text { School Characteristics } \\
\text { Enrollment }\end{array}$ & 619.59 & 632.34 & -0.072 & -0.85 & $0.397^{* * *}$ & 0.77 \\
\hline Share ELL & 0.41 & 0.41 & -0.017 & -0.2 & $0.841^{* * *}$ & 1.49 \\
\hline Share Hispanic & 0.68 & 0.72 & -0.172 & -1.96 & $0.05^{* *}$ & 1.15 \\
\hline Share SPED & 0.07 & 0.07 & 0.09 & 0.96 & $0.335^{* * *}$ & 1.04 \\
\hline Average Teacher Years of Experience & 10.69 & 10.99 & -0.112 & -1.13 & $0.257^{* * *}$ & 0.86 \\
\hline Number of Bilingual Teachers & 24.24 & 28.67 & -0.255 & -2.5 & $0.013^{* * *}$ & 0.78 \\
\hline Bilingual Program Indicator & 0.9 & 0.94 & -0.107 & -1.47 & $0.142^{* * *}$ & -- \\
\hline $\begin{array}{c}\text { School Outcomes } \\
\text { School Average Math Score }\end{array}$ & 590.62 & 592.07 & -0.05 & -0.56 & $0.578^{* * *}$ & 1.08 \\
\hline School Average ELL Math score & 586.74 & 587.76 & -0.028 & -0.3 & $0.764^{* * *}$ & 1.02 \\
\hline School Average ELA Score & 601.15 & 599.41 & 0.054 & 0.61 & $0.539^{* * *}$ & 1.26 \\
\hline School Average ELL ELA Score & 587.26 & 586.19 & 0.025 & 0.26 & $0.793^{* * *}$ & 0.87 \\
\hline $\begin{array}{c}\text { District Characteristics } \\
\text { District Enrollment }\end{array}$ & $31,360.03$ & $29,779.48$ & 0.039 & 0.69 & $0.488^{* * *}$ & 0.74 \\
\hline Share ELL & 22.44 & 21.03 & 0.112 & 1.26 & $0.21^{* *}$ & 1.76 \\
\hline Per Pupil Expenditure & $10,924.73$ & $11,211.18$ & -0.118 & -1.33 & $0.183^{* * *}$ & 3.77 \\
\hline Total Revenue Per Pupil & $1,348.79$ & $1,399.63$ & -0.093 & -0.92 & $0.36^{* *}$ & 1.4 \\
\hline Urbanicity & 4.08 & 3.93 & 0.051 & 0.5 & $0.618^{* * *}$ & 0.58 \\
\hline $\begin{array}{c}\text { District Outcomes } \\
\text { District Avg TELPAS Score }\end{array}$ & 3.08 & 3.08 & -0.004 & -0.04 & $0.966^{* * *}$ & 0.93 \\
\hline District Average Math Score & 596.02 & 595.68 & 0.018 & 0.2 & $0.844^{* * *}$ & 1.03 \\
\hline District Avg Math Score for ELLs & 587 & 587.13 & -0.006 & -0.07 & $0.945^{* * *}$ & 1.61 \\
\hline District Average ELA Score & 609.87 & 608.22 & 0.077 & 0.87 & $0.384^{* * *}$ & 1.07 \\
\hline District Avg ELA Score for ELLs & 587.98 & 585.54 & 0.104 & 1.12 & $0.262^{* * *}$ & 1.46 \\
\hline $\begin{array}{c}\text { District-Area Characteristics (Census) } \\
\text { Median Household Income }\end{array}$ & 47,976.89 & $46,785.11$ & 0.08 & 0.82 & $0.413^{* * *}$ & 1.09 \\
\hline Share Non-English Speakers & 42.85 & 43.21 & -0.014 & -0.15 & $0.879^{* * *}$ & 1.13 \\
\hline Propensity score & 0.34 & 0.34 & 0 & 0.00 & $0.997^{* * *}$ & 1 \\
\hline
\end{tabular}

Notes. ${ }^{* *} \mathrm{p}<0.01 ;{ }^{* * *} \mathrm{p}<0.001$.

Following Rubin (2001), we calculate the standardized difference in the mean propensity score in the two groups. To minimize bias, the standardized difference should be zero or close to zero. Though there are no formal criteria for evaluating standardized differences, Rosenbaum and Rubin (2001) suggest that values greater than 0.20 should be interpreted as large. The standardized difference for the propensity score is 0.001 for both research questions.

Second, we calculate the variance ratios of the propensity score distribution in the treatment and control groups 
(Rubin 2001). To minimize bias, the variance ratios should ideally lie between 0.8 and 1.25 . Variance ratios smaller than 0.5 or greater than 2.0 are considered extreme (Rubin, 2001). The variance ratio of the propensity scores are 1.00 for both research questions.

We extend the first two balancing tests to include individual covariates. Though Rubin (2001) recommends balancing on propensity score alone, we also calculate the standardized difference and variance ratio for each covariate in the propensity score model. By doing so, we can gain a more robust understanding of the comparability of the control and treatment groups. For the first research question, we find that the variance ratio for all covariates is in the range of acceptability [0.5, 2.0] except for district per pupil expenditure which has a variance ratio of 3.77 . State-adopters have a wider range of per pupil expenditures than non-adopters. For the second research question, the variance ratio for share of EBs is 0.45 which is slightly outside the range of acceptability. Schools that adopt National Geographic Reach have a larger range of percentage of EBs compared to school that adopt Rigby On Our Way to English. The absolute value of the standardized difference is less than 0.20 for all covariates except for the number of bilingual teachers which has a standardized difference of -0.26 . For the first research question, non-adopters, on average, have 29 bilingual teachers while state-adopters average 24 bilingual teachers per campus.

Third, we present results from hypothesis tests. Though hypothesis tests and p-values should not be used as measures of balance (Ho, Imai, King, \& Stuart, 2007; Stuart, 2010), they are still common in balancing tests. Results from hypothesis testing may be misleading since small differences in means may be statistically significant in a large sample. Though results from hypothesis tests are not given much consideration, we present them to create a more robust understanding of covariate balance. For the first research question, treatment and control schools differ significantly on one variable - number of bilingual teachers. For the second research question, treatment and control schools differ significantly on two variables - number of bilingual teachers and median household income.

Overall, these tests suggest that the individual covariates and the propensity scores are well balanced between treated and control units. The standardized difference for the propensity score is 0.001 the variance ratio is 1 for both balancing tests.

\subsection{Matching Algorithm}

Matching algorithms assume that the outcome variable is independent of treatment assignment conditional on a set of observable characteristics (Smith \& Todd, 2005). In addition, it is assumed that for all conditioning variables, there is a positive probability of assignment to treatment or control conditions. This assumption implies that a match can be found for all treated cases. Matching estimators perform well in replicating the results of a randomized control trial when the following criteria are met: 1). the same data sources are used for both control and treated units, 2). control and treated units reside in the same labor market, and 3). the data contain a rich set of covariates that impact both treatment assignment and the outcome variable (Heckman, Ichimura, \& Todd, 1997; Heckman et al., 1998; Smith \& Todd, 2005). There is strong evidence suggesting that all three conditions are met in this study. First, covariates and outcome variables are the same for both treatment and control schools and is also measured in the same way for both groups. Second, all treatment and control schools reside in the same geographic area-Texas. Third, conditioning variables adjust for a wide array of characteristics - reading and math achievement, English proficiency, teacher quality, demographic characteristics, and median household income. Since these foundational requirements have been met, it is appropriate to proceed with matching.

We choose local linear matching (LLR) over other matching methods for three main reasons. First, local linear matching can reduce variance relative to other matching techniques because it relies on more information. While common matching techniques like nearest neighbor matching only use a few observations from the comparison group to construct the counterfactual, local linear matching uses a weighted average of comparison units near the treatment unit. Since more information is used, there is lower variance which leads to more precise estimates of the treatment effect. Second, local linear matching includes a linear term in the propensity while kernel matching does not. This added intercept is an advantage whenever there are gaps in the propensity score. Lastly, local linear matching relies on weaker assumptions compared to other matching approaches. Rosenbaum and Rubin's (1983) framework for propensity score matching requires strongly ignorable treatment assignment and common support; kernel-based matching methods such as local linear matching replaces these two assumptions with weaker ones (Heckman et al., 1998). Instead of assuming strongly ignorable treatment assignment, Heckman and colleagues only require that the outcome under the control condition for the treated cases to be independent of the treatment assignment, conditional on observed covariates (Guo \& Fraser, 2010). Instead of assuming full independence, Heckman and colleagues 
impose mean independence. Though local linear matching is our method of choice, we also include results from kernel matching, inverse probability weighting with regression adjustment (IPW-RA), and nearest neighbor matching with 1, 2, and 3 neighbors (which will be abbreviated K1, K2, and K3, respectively).

Following Dehejia and Wahba (2002), we trim the sample as needed to determine the support region. There are no control units below the minimum propensity score for treated units for either research question. We also assess for common support by visually inspecting a probability density distribution of the propensity score in both groups. Lechner (2000b) argues that common support can be assessed visually, and there is no need to implement more complicated, formal processes. Estimated density functions of the propensity scores for treatment and control schools (available upon request) show strong evidence of common support.

\section{Results}

\subsection{Research Question 1: Non-Adopters vs. State-Adopters}

Using local linear matching, we compare the effect of not purchasing an ELI text to the effect of purchasing a state-adopted ELI text. We find that elementary schools that do not purchase any elementary ELI texts score 0.30 standard deviations lower on school-average TELPAS composite scores (see Table 5).

Table 5. Average treatment effects of non-adoption relative to state-adopted ELI instructional materials on TELPAS spring 2015 composite scores

\begin{tabular}{|c|c|c|c|c|c|c|}
\hline & LLR & Kernel & IPWRA & K1 & K2 & K3 \\
\hline \multirow{2}{*}{$\begin{array}{c}\text { Treatment } \\
\text { effect }\end{array}$} & $-0.30^{*}$ & $-0.31^{*}$ & $-0.35^{* * *}$ & $-0.28^{* * *}$ & $-0.33^{* * *}$ & $-0.35^{* * *}$ \\
\hline & $(0.15)$ & $(0.15)$ & $(0.07)$ & $(0.09)^{* *}$ & $(0.08)$ & $(0.07)$ \\
\hline N (schools) & 1,024 & 1,024 & 1,024 & $1,024^{* * *}$ & 1,024 & 1,024 \\
\hline
\end{tabular}

Notes. Standard errors are in parentheses. Standard errors are estimated by bootstrapping using 250 repetitions and clustered at the district level for the local linear and kernel matching models. Robust standard errors are calculated for K1 matching and IPWRA models. ${ }^{*} \mathrm{p}<0.05$; ${ }^{* *} \mathrm{p}<0.01$; ${ }^{* * * *} \mathrm{p}<0.001$.

Following Bhatt, Koedel, and Lehman (2013), standard errors are estimated by bootstrapping using 250 repetitions and clustered at the district level.

To address the robustness of the findings, we compare results across all matching models. The results from the kernel matching estimator are similar to the estimates from the local linear matching model with non-adopters scoring 0.31 standard deviations lower than state-adopters. Results from the IPWRA and nearest neighbor matching models are similar in magnitude with non-adopters scoring 0.28-0.35 standard deviations lower than state-adopters. The standard errors in these models are roughly half the size of the standard errors in the local linear matching model. One reason for the large standard errors for the LLR and kernel matching models may be due to the use of bootstrapping methods. The nearest neighbor matching and IPW-RA models rely on Abadie-Imbens standard errors (Abadie \& Imbens, 2008) instead of bootstrapped standard errors.

Regardless of the type of matching estimator used, a common pattern emerges across all six models; schools that do not adopt any ELI curricula score have TELPAS composites scores that are roughly 0.30 standard deviations lower than schools that purchase state-adopted ELI curricula. As previously mentioned, these results are only generalizable to schools in Texas whose TELPAS scores are not masked, use the same ELI curricula in grades K-3, and who did not have missing textbook data.

\subsection{Research Question 2: Rigby On Our Way to English vs. National Geographic Reach}

When comparing the Rigby on Our Way to English curricula to National Geographic (NG) Reach, we find that schools that use Rigby have slightly higher TELPAS composite scores in all outcome models but these differences are not statistically significant (see Table 6).

The standard errors for these estimates are slightly larger than the standard errors for the previous research question due to the difference in sample size. It is possible that there is a treatment effect in the population; however, this study may not be able to identify the treatment effect given the limited sample size. Relatedly, this study was not able to assess the effectiveness of any other ELI curricula due to small sample size.

The nonsignificant differences in TELPAS scores between Rigby-adopters and NG-adopters is, for the most part, 
mirrored in the kernel matching, IPWRA, and K-1 matching models. However, the K-2 and K-3 matching models find that Rigby-adopters have significantly higher TELPAS composite scores. According to the K-2 and K-3 matching models, Rigby users score 0.16 standard deviations higher on TELPAS composite scores relative to schools that adopt National Geographic Reach. The standard errors are smaller in the K2 and K3 models because there is more information being used. However, these estimates should be interpreted with caution as bias increases as more control units are matched to each treated unit.

Table 6. Average treatment effects of Rigby On Our Way to English relative to National Geographic Reach on TELPAS spring 2015 composite scores

\begin{tabular}{ccccccc}
\hline & LLR & Kernel & IPWRA & K1 & K2 & K3 \\
\hline Treatment effect & 0.05 & 0.05 & 0.14 & $0.13^{* *}$ & $0.16^{*}$ & $0.17^{*}$ \\
N (schools) & $(0.17)$ & $(0.16)$ & $(0.08)$ & $(0.08)^{* *}$ & $(0.07)$ & $(0.07)$ \\
\hline
\end{tabular}

Notes. Standard errors are in parentheses. Standard errors are estimated by bootstrapping using 250 repetitions and clustered at the district level for the local linear and kernel matching models. Robust standard errors are calculated for K1 matching and IPWRA models. ${ }^{*} \mathrm{p}<0.05 ;{ }^{* *} \mathrm{p}<0.01$; ${ }^{* * * *} \mathrm{p}<0.001$.

\subsection{Falsification Tests}

Propensity score matching will not provide causal estimates if the conditional independence assumption (CIA) is violated. The CIA can be violated if there are systematic differences in school or district quality across the various curriculum adopters that captured by the covariates in the model. If these differences are correlated with curriculum adoptions and student achievement, then the estimates may be biased. For example, if there are differences in commitment to improving achievement for EBs across the various curriculum adopters, this could bias the estimates. Though it is impossible to rule out all possible sources of bias, we provide evidence about the general reliability of the findings using two falsification tests.

First, we estimate ELI curriculum effects on math achievement for $3^{\text {rd }}$ grade EBs (see Table 7).

Table 7. Falsification Tests: Effects of Non-Adoption versus State-Adoption on STAAR 2015 Math Achievement

\begin{tabular}{cccccccc}
\hline & LLR & Kernel & IPWRA & K1 & K2 & K3 \\
\hline Treatment effect & -0.04 & -0.06 & 0.01 & $0.10^{* *}$ & 0.10 & 0.09 \\
N (schools) & $(0.13)$ & $(0.13)$ & $(0.07)$ & $(0.08)^{* *}$ & $(0.08)$ & $(0.08)$ \\
\hline
\end{tabular}

Notes. Standard errors are in parentheses. Standard errors are estimated by bootstrapping using 250 repetitions and clustered at the district level for the local linear and kernel matching models. Robust standard errors are calculated for K1 matching and IPWRA models. ${ }^{* *} \mathrm{p}<0.01 ;{ }^{* * *} \mathrm{p}<0.001$.

If there are unobserved differences across adopters that are not captured by the covariates in the model, then we might see significant differences between treated and control units on math scores for $3^{\text {rd }}$-grade EBs in 2015. The confounding factor (e.g., commitment to improving educational outcomes for EBs) will be present in the form of non-zero curriculum effects. If curriculum effects are not significantly different from zero for unexposed cohorts, then it is the curricula themselves, not other unobserved differences, that are driving the estimates. Since English language proficiency is correlated with math achievement (Grant, Cook, \& Phakiti, 2011), it is possible that non-adopters have lower math achievement than state-adopters. At most, these spillover effects will be small and no larger than the effects from the main findings. We find that schools that do not adopt any ELI curricula score 0.04 standard deviations lower on the state math test than scores that do adopt ELI curricula; however, this difference is not significant. Indeed, these spillover effects are smaller than the main treatment effect of 0.30 standard deviations. While the estimates from the kernel and local linear matching models are negative, the other models yield positive treatment effects on STAAR 2015 math achievement. However, these differences are not concerning as the magnitude of the estimates are relatively small and non-significant. There appears to be no evidence that the primary findings are driven by unobserved differences between non-adopters and state-adopters.

In the second falsification test, we use $3^{\text {rd }}$ grade TELPAS scores from spring 2012 as the outcome variable. By the end of the 2011-2012 school year, $3^{\text {rd }}$-graders will have been exposed to the ELI curricula for no more than one year. 
Since ELI curricular materials were adopted during the 2011-2012 school year, it is unlikely that the materials had a large impact on English proficiency less than a year after implementation. If there are significant curricular impacts, then the impact should be smaller in magnitude than the impact on TELPAS spring 2015 scores. Indeed, there are no significant differences between $3^{\text {rd }}$ graders in treatment and control schools during the 2012 TELPAS test (see Table 8). In addition, the estimates are all negative which is consistent with the finding from the main analysis that non-adoption is associated with lower English language proficiency. Less than one year after implementation, we find that non-adopters score 0.09 standard deviations lower than state-adopters on the state English language proficiency test; however, this difference is not significant.

Table 8. Falsification Tests: Effects of Non-Adoption versus State-Adoption on 2011-2012 $3^{\text {rd }}$-grade TELPAS Composite Scores

\begin{tabular}{ccccccc}
\hline & LLR & Kernel & IPWRA & K1 & K2 & K3 \\
\hline Treatment effect & -0.09 & -0.06 & -0.02 & $-0.05^{* *}$ & -0.06 & -0.07 \\
N (schools) & $(0.16)$ & $(0.16)$ & $(0.08)$ & $(0.09)^{* *}$ & $(0.08)$ & $(0.08)$ \\
& 1,037 & 1,037 & 1,037 & $1,037^{* * *}$ & 1,037 & 1,037 \\
\hline
\end{tabular}

Notes. Standard errors are in parentheses. Standard errors are estimated by bootstrapping using 250 repetitions and clustered at the district level for the local linear and kernel matching models. Robust standard errors are calculated for K1 matching and IPWRA models. ${ }^{* *} \mathrm{p}<0.01$; ${ }^{* * *} \mathrm{p}<0.001$.

We also modeled the data using an alternative approach, employing a comparative interrupted time series (CITS) model to estimate the impact of ELI adoption on English language proficiency. In the CITS regression, we adjust for the same school and district characteristics that are used in the propensity score estimation. The results from the CITS model mirrors the results from the local linear matching model with non-adopters scoring 0.30 standard deviations lower than state-adopters $(\mathrm{p}<0.01)$. With regards to the second research question, the CITS model reveals no significant differences in spring 2015 English language proficiency score between schools that adopt Rigby and schools that adopt National Geographic. Given the robustness of results across various quasi-experimental methods, there is strong evidence to suggest that state-adopted ELI textbooks have a positive impact on EBs' English language proficiency.

In sum, both falsification tests point towards the validity of the findings. None of the tests suggests that there are systematic differences between treatment and control schools. In addition, we employed a different type of quasi-experimental method-comparative interrupted time series-and recovered similar treatment effects for both research questions.

\section{Discussion}

There are four main reasons to believe that the estimates are unbiased. First, we use multiple balancing tests to assess balance, and all tests show that the covariates are well balanced. The standardized difference of the propensity score is nearly zero and the variance ratio is close to 1 . Second, we include pretest measures of the outcome variable, which some researchers argue is the most important factor in propensity score analysis (Shadish \& Steiner, 2010). Third, through interviewing district leaders in Texas, we are able to study the selection process. This allows us to choose a rich set of relevant covariates to estimate the propensity score. Fourth, the treatment effect remains robust across various matching models and a CITS regression.

It is also important to discuss what this study is not suggesting. This study does not suggest that off-list ELI materials, or ELI materials that are not on the state-adopted list, are ineffective for ELI instruction. Off-list ELI curricula such as EL Achieve and Carousel of IDEAS may also be effective but due to small sample size we were not able to evaluate the effectiveness of off-list texts.

\section{Conclusion}

This study makes two contributions to the research literature on curricular effectiveness. This study is the first to assess the effectiveness of ELI curricular materials at the state level. Prior studies on textbook effectiveness have focused on math textbooks. Furthermore, this study makes use of a unique dataset comprised of ELI curricular materials adoptions in the state of Texas. No prior studies have looked at curricular effectiveness in Texas. Texas is an appropriate state for the proposed study as it services the second highest number of EBs in the United States. Second, the study contributes to the larger research literature on English language development which is sparse. Saunders, Goldenberg, and Marcelletti (2008) conduct the most comprehensive review of ELI instructional practices and find 
that little research examines the effects of ELI instruction on EBs' academic achievement. In fact, since ELI research is so scant, the authors had to rely on second language research in other fields to inform their ELI guidelines. For example, some of the studies included in their synthesis focused on English learners in Quebec, Canada. This study contributes directly to the research literature on ELI because it focuses on English language learners in the United States.

The current study is not able to capture the variation across and within districts with regards to ELI curriculum implementation. It is likely that the impact of ELI curriculum on EBs' achievement is mediated by the degree of implementation. If there is a significant relationship between degree of implementation and EBs' academic outcomes, then it is important to understand the nature of that relationship. Furthermore, if implementation fidelity is mediated by certain factors (e.g., practitioners' beliefs about second language acquisition), then it is of import to identify these mediating factors so that barriers to implementation can be addressed.

Qualitative data from interviews with district leaders reveal that there is confusion about the purpose of ELI instruction and how it differs from instruction for monolingual English-speakers. For instance, some district leaders believe that instruction for EBs is "just good teaching" (JGT), and, therefore, there is no need to purchase materials specifically for EBs. In other words, whatever works for monolingual English-speakers is sufficient to address the academic and linguistic needs of EBs. This finding is not new as previous research has found that a "just good teaching” approach is not adequate to meet the academic and linguistic needs of EBs (De Jong \& Harper, 2005). Ten years after De Jong and Harper coined the term JGT to describe this phenomenon, we find that the JGT view of teaching EBs is still pervasive. In short, we reiterate De Jong and Harper's (2005) call to explicitly include EBs at all levels of educational policy and practice. If there are expectations that content standards be explicitly and rigorously addressed, the same expectation should exist for English language proficiency standards. Otherwise, a double standard exists based on language which is effectively a proxy for national origin (Lau v. Nichols, 1974).

Castañeda v. Pickard (1981) mandated that educational programs for EBs be tested for program efficacy, which is what we attempt to do in this study. Using local linear matching, we find that students in non-adopting districts have lower English proficiency relative to those in state-adopting districts. Schools that do not have curricula that foreground English language proficiency should consider obtaining instructional materials that explicitly address forms of English, provide ample opportunities to develop all four language modalities, and integrate conversational and academic language. Though there is evidence to suggest that ELI instructional materials can improve English language proficiency, much more work needs to be done to adequately meet the academic and linguistic needs of EBs (e.g., tracking of EBs, resegregation efforts that concentrate EBs in low-income schools). Implementing high quality ELI curricula is only one part of an educational agenda that seeks to redress educational inequities faced by emergent bilinguals.

\section{References}

Abadie, A., \& Imbens, G. W. (2008). On the failure of the bootstrap for matching estimators. Econometrica, 76(6), 1537-1557.

Agodini, R., Harris, B., Thomas, M., Murphy, R., \& Gallagher, L. (2010). Achievement Effects of Four Early Elementary School Math Curricula: Findings for First and Second Graders. NCEE 2011-4001. National Center for Education Evaluation and Regional Assistance.

Alajmi, A. H. (2009). Addressing computational estimation in the Kuwaiti curriculum: teachers' views. Journal of Mathematics Teacher Education, 12(4), 263-283.

Alajmi, A. H. (2012). How do elementary textbooks address fractions? A review of mathematics textbooks in the USA, Japan, and Kuwait. Educational Studies in Mathematics, 79(2), 239-261..

Arnold, J. (Ed.). (1999). Affect in language learning. Ernst Klett Sprachen.

Bhatt, R., \& Koedel, C. (2012). Large-scale evaluations of curricular effectiveness: The case of elementary mathematics in Indiana. Educational Evaluation and Policy Analysis, 34(4), 391-412

Bhatt, R., Koedel, C., \& Lehmann, D. (2013). Is curriculum quality uniform? Evidence from Florida. Economics of Education Review, 34, 107-121.

Black, D. A., \& Smith, J. A. (2004). How robust is the evidence on the effects of college quality? Evidence from matching. Journal of econometrics, 121(1-2), 99-124. 
Blazar, D., Heller, B., Kane, T. J., Polikoff, M., Staiger, D., Carrell, S., ... \& Kurlaender, M. (2019). Learning by the book: Comparing math achievement growth by textbook in six Common Core states.

De Jong, E. J., \& Harper, C. A. (2005). Preparing mainstream teachers for English-language learners: Is being a good teacher good enough?. Teacher Education Quarterly, 32(2), 101-124.

Dehejia, R. H., \& Wahba, S. (2002). Propensity score-matching methods for nonexperimental causal studies. Review of Economics and statistics, 84(1), 151-161.

Education Week. (2011). English-Language Learners. Accessed October 2, 2015, http://www.edweek.org/ew/issues/english-language-learners/.

García, O. (2009). Emergent Bilinguals and TESOL: What's in a Name?. Tesol Quarterly, 43(2), 322-326.

Genesee, F., Lindholm-Leary, K., Saunders, W., \& Christian, D. (2005). English language learners in US schools: An overview of research findings. Journal of Education for Students Placed at Risk, 10(4), 363-385.

Glazerman, S., Levy, D. M., \& Myers, D. (2003). Nonexperimental versus experimental estimates of earnings impacts. The Annals of the American Academy of Political and Social Science, 589(1), 63-93.

Grant, R., Cook, H. G., \& Phakiti, A. (2011). Relationships between language proficiency and mathematics achievement. Madison, WI: WIDA Consortium.

Guo, S., \& Fraser, M. W. (2014). Propensity score analysis: Statistical methods and applications (Vol. 11). SAGE publications.

Heckman, J. J., Ichimura, H., \& Todd, P. (1998). Matching as an econometric evaluation estimator. The review of economic studies, 65(2), 261-294.

Heckman, J. J., Ichimura, H., \& Todd, P. E. (1997). Matching as an econometric evaluation estimator: Evidence from evaluating a job training programme. The review of economic studies, 64(4), 605-654.

Ho, D. E., Imai, K., King, G., \& Stuart, E. A. (2007). Matching as nonparametric preprocessing for reducing model dependence in parametric causal inference. Political analysis, 15(3), 199-236

Horwitz, E. K. (1999). Cultural and situational influences on foreign language learners' beliefs about language learning: A review of BALLI studies. System, 27(4), 557-576.

Jassim, L. L. (2015). Analysis of Semantic Errors in Iraqi EFL Learners’ writings. The Journal of University of ThiQar, 11(4): 184-162.

Jassim, L. L. (2016). Investigation of Sequential Progression Topics in Iraqi EFL Students' Writing. The Journal of University of ThiQar, 10(3): 47-63.

Koedel, C., Li, D., Polikoff, M. S., Hardaway, T., \& Wrabel, S. L. (2017). Mathematics curriculum effects on student achievement in California. Aera Open, 3(1), 2332858417690511.

Le, Q. T., \& Polikoff, M. (n.d.). The effects of English language development curriculum materials on students’ English proficiency. http://www.tea.texas.gov/WorkArea/DownloadAsset.aspx?id=2147502085.

Menken, K., \& Solorza, C. (2014). No child left bilingual: Accountability and the elimination of bilingual education programs in New York City schools. Educational Policy, 28(1), 96-125.

Namey, E., Guest, G., Thairu, L., \& Johnson, L. (2008). Data reduction techniques for large qualitative data sets. Handbook for team-based qualitative research, 2(1), 137-161.

Orfield, G. (2001). Schools more separate: Consequences of a decade of resegregation.

Orfield, G., \& Lee, C. (2006). Racial transformation and the changing nature of segregation.

Rios-Aguilar, C., \& Gandara, P. (2012). Horne v. Flores and the future of language policy. Teachers College Record, 114(9).

Robitaille, D. F., \& Travers, K. J. (1992). International studies of achievement in mathematics.

Rosenbaum, P. R., \& Rubin, D. B. (1983). The central role of the propensity score in observational studies for causal effects. Biometrika, 70(1), 41-55.

Rubin, D. B. (2001). Using propensity scores to help design observational studies: application to the tobacco litigation. Health Services and Outcomes Research Methodology, 2(3-4), 169-188.

Saldaña, J. (2015). The coding manual for qualitative researchers. Sage.

Shadish, W. R., \& Steiner, P. M. (2010). A primer on propensity score analysis. Newborn and Infant Nursing Reviews, 
10(1), 19-26.

Shadish, W. R., Cook, T. D., \& Campbell, D. T. (2002). Experimental and quasi-experimental designs for generalized causal inference/William R. Shedish, Thomas D. Cook, Donald T. Campbell. Boston: Houghton Mifflin.

Smith, J. A., \& Todd, P. E. (2005). Does matching overcome LaLonde’s critique of non-experimental estimators?. Journal of econometrics, 125(1-2), 305-353.

Snyder, T. D., De Brey, C., \& Dillow, S. A. (2019). Digest of Education Statistics 2017, NCES 2018-070. National Center for Education Statistics.

Stein, M., Stuen, C., Carnine, D., \& Long, R. M. (2001). Textbook evaluation and adoption. Reading \& Writing Quarterly, 17(1), 5-23.

Steiner, P. M., \& Cook, D. (2013). Matching and propensity scores. The Oxford handbook of quantitative methods, 1, 237-259.

Stuart, E. A. (2010). Matching methods for causal inference: A review and a look forward. Statistical science: a review journal of the Institute of Mathematical Statistics, 25(1), 1.

Texas Education Agency. (2014). "Reports and Data.” Accessed October 1, 2015, http://tea.texas.gov/Reports_and_Data/.

Texas Education Agency. (2015a). A Brief Overview of the Adoption Process. http:/tea.texas.gov/interiorpage. aspx?id=2147485614.

Texas Education Agency. (2015b). Interpreting Assessment Reports. http:/tea.texas.gov/student.assessment/interpguide/.

Texas Education Agency. (2016). Texas English Language Proficiency Assessment System. Texas Education Agency.

Van Roekel, D. (2008). English language learners face unique challenges. An NEA Policy Brief. National Education Association.

Zeringue, J., K., Deborah, S., June, M., K., \& M. A. Newton. (2010). Influences on mathematics textbook selection: What really matters. San Diego, CA: NCTM Research Pre-session. 